\title{
A Quantitative Analysis of the Relationship Between Congestion and Reliability in Electric Power Networks
}

\author{
Seth Blumsack ${ }^{1}$, Lester B. Lave ${ }^{2}$, Marija Ilic ${ }^{3}$
}

\begin{abstract}
Restructuring efforts in the U.S. electric power sector have tried to encourage transmission investment by independent (non-utility) transmission companies, and have promoted various levels of market-based transmission investment. Underlying this shift to "merchant" transmission investment is an assumption that new transmission infrastructure can be classified as providing a congestion-relief benefit or a reliability benefit. In this paper, we demonstrate that this assumption is largely incorrect for meshed interconnections such as electric power networks. We focus on a particular network topology known as the Wheatstone network to show how congestion and reliability can represent tradeoffs. Lines that cause congestion may be justified on reliability grounds. We decompose the congestion and reliability effects of a given network alteration, and demonstrate their dependence through simulations on a 118-bus test network. The true relationship between congestion and reliability depends critically on identifying the relevant range of demand for evaluating any network externalities.
\end{abstract}

1. Corresponding author. Tepper School of Business, Carnegie Mellon University, Pittsburgh PA 15213. Tel: +1 412-268-9178, e-mail: blumsack@cmu.edu.

2. Tepper School of Business and Department of Engineering and Public Policy, Carnegie Mellon University.

3. Department of Electrical and Computer Engineering and Engineering and Public Policy, Carnegie Mellon University. 


\section{Introduction: Transmission Investment in the Old and New Electricity Industry}

One distinct difference between restructured and traditionally-organized electric power systems is the way in which congestion is managed. Grid operators in many areas where restructuring has not occurred use a command-and-control procedure known as transmission loading relief (TLR), which physically manages constraints by rationing access to portions of the transmission network. Independent System Operators (ISO) or Regional Transmission Organizations (RTO) on the other hand, generally use marketbased methods to manage congestion. Of particular concern to policymakers and system planners is that both metrics indicate that stress on the system has risen dramatically, particularly since the beginning of restructuring. Congestion costs have risen on both a gross and average level in the PJM market (Blumsack 2006a, Ch. 1), while the incidence of TLRs has risen by a factor of five (Joskow 2005a, Blumsack, Apt, and Lave 2006).

In the regulated electricity industry, the transmission system is essentially a vehicle for the delivery of bulk power. The transmission network could also act as a physical hedge against unplanned generator outages. Either way, the main purpose of utility transmission planning was to support system reliability. Reliability reflects the goal that the system should be redundant enough to avoid service interruptions even in the face of contingencies. Examples of some common reliability metrics are:

1. The $N-k$ criterion; whether the system can continue to provide uninterrupted service to customers in the face of a contingency in which $k$ out of $N$ pieces of equipment are lost, damaged, or otherwise disconnected from the network;

2. the Loss of Load Probability (LOLP), defined as the probability over some period of time that the network will fail to provide uninterrupted service to customers;

3. the Loss of Energy Expectation (LOEE) and Loss of Energy Probability (LOEP), defined as the expected amount and proportion of customer demand not served over some time frame. These are also known as the Unserved Energy Expectation or Probability.

Transmission planning in the regulated industry represented one step in an overall integrated resource plan, in which utilities ensure resource adequacy in generation, transmission, and distribution for a given set of peak and seasonal demand scenarios (Coxe and Ilić 1998). Under industry restructuring, an increasing number of investment decisions have been made by decentralized market participants (such as independent power producers), and not the vertically-integrated utility. Baldick and Kahn (1993) outline how issues of economics and externalities, formerly handled within the utility planning process, may yield different or conflicting solutions in the context of markets and open transmission access. Transmission companies must also accommodate energymarket outcomes into their investment decisions. Thus, whereas prices in the regulated environment were an output of the planning process (and were determined largely by the decisions of regulators), prices in the restructured era have become inputs to the planning process (Coxe and Ilić 1998). Prices in the energy market must solve both the short-run operations problem (clearing the hourly or daily market for electric energy) and the longrun investment problem (Yu, Leotard, and Ilić 1999, Blumsack 2006a, Ch. 1). 
Just as a non-utility or "merchant" generation sector emerged following the passage of the Energy Policy Act of 1992, restructuring brought with it the potential for a merchant transmission sector. These transmission-only companies would build lines in RTO territories in response to congestion pricing signals (Joskow and Tirole 2005), and would be compensated with financial or physical congestion rights associated with any incremental capacity created by their investments. Hogan (1992) proposed a system of point-to-point financial transmission rights (FTR), which would grant the holder the right to the difference in locational prices between any two points on the grid. Thus, the value of an FTR can be determined as a by-product of the energy market; this allows market participants to hedge locational price risk (Aruqui et. al. 2005, Patiño-Echeverri and Morel 2006). The analysis of Chao and Peck (1996) introduced the concept of tradable "flowgate" rights, which would associate congestion payments with physical congestion on specified paths. More recently, Gribik et. al. (2005) have considered augmenting the flowgate model to separate payments into a capacity component and a component reflecting the physical aspects of transmission lines (such as admittance). Apt and Lave (2003) propose a two-part tariff for transmission investment, which would combine locational pricing with the megawatt-mile charge described in Yu and David (1997) for long-run marginal cost pricing. Vogelsang $(2001,2004)$ has advocated performancebased regulation for non-utility transmission, while Lecinq and Ilić (1997) describe a possible peak-load pricing formulation for transmission, based on the work of Crew and Kleindorfer (1979) for the regulation of public utilities.

Proponents of both FTRs and flowgates have argued that congestion rights can be used to promote merchant transmission investment. Bushnell and Stoft $(1996,1997)$ show that if transmission investors are compensated with incremental FTRs, merchant transmission investment will be economically efficient (in the sense that profitable investments will also be beneficial to the network), as long as the FTRs are allocated according to the "feasibility rule."1 Oren (1997) argues that using congestion contracts tied to market prices favors generators with market power, and that the use of tradeable flowgate rights removes localized market power associated with network constraints. The dominant merchant transmission model, based on FTRs, has been criticized for failing to account for system dynamics driven by uncertainty in demand, as in Yu, Leotard, and Ilić (1999). Joskow and Tirole (2005) find that efficiency of the merchant transmission model is not robust to deviations from the underlying economic assumptions.

Underlying the merchant transmission model, as well as variations like the "participant funding" model (Hebert 2004, Roark 2006), is an implicit assumption that a distinction can be drawn between "economic" investments (which primarily relieve congestion along a readily-identifiable portion of the network) and "system" investments (which promote reliability). A related distinction divides projects into those affecting a reasonably small number of identifiable network participants and those affecting the entire network. Transmission policy, both at the RTO level and at FERC, has encouraged planners to

\footnotetext{
${ }^{1}$ The feasibility rule allocates FTRs in such a way as to respect all the network constraints; it was originally devised by Hogan (1992) to ensure that the RTO's FTR obligations did not exceed its congestion revenues.
} 
make either or both of these distinctions, and to emphasize the congestion and competitive effects of new power lines (Awad et. al. 2004, Sauma and Oren 2006). ${ }^{2}$

Joskow (2005b) has argued that attempts to divide transmission investments into congestion-relief and reliability categories, as in Hogan (2003) and Shanker (2003), amounts to a meaningless dichotomy, since most investments have been made (and will continue to be made) by regulated utilities driven by reliability criteria. This paper goes one step further and provides a quantitative analysis of the degree to which congestion and reliability are independent system attributes. We find that the dichotomy is not simply meaningless. In many cases, it is wrong. Increasing network reliability by adding new AC transmission lines can actually increase congestion (though in some instances the two are complementary - congestion can be reduced and reliability enhanced with a single line). Further, this relationship is a function of both the network topology and the level of demand. The degree to which congestion and reliability represent tradeoffs faced by system planners and investors is more pronounced for some network topologies than others. Assessing whether a given transmission project has significant externalities (positive or negative) depends on identifying the relevant range of demand.

\section{Wheatstone Networks and the Braess Paradox}

Consider the four-bus test network shown in Figure 1. There are two generators in the system, at buses 1 and 4; each is assumed to have a capacity of $100 \mathrm{MW}$. The load at bus 4 has a constant real power demand (denoted $P_{L i}$ ) of $100 \mathrm{MW}$. There is no other net demand in the system. Buses 2 and 3 are merely tie-points, with neither net generation nor load. The four transmission lines in the network are all rated to $55 \mathrm{MW}{ }^{3}$ Lines $S_{12}$ and $S_{34}$ have identical admittances, and lines $S_{13}$ and $S_{24}$ have identical admittances.

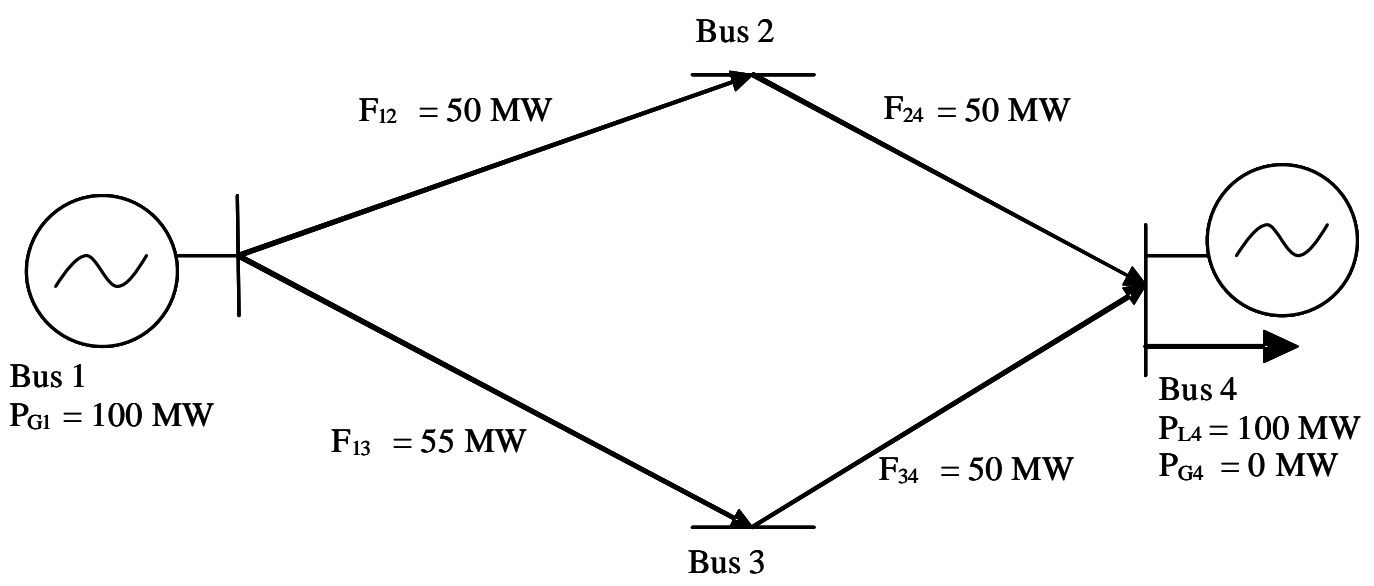

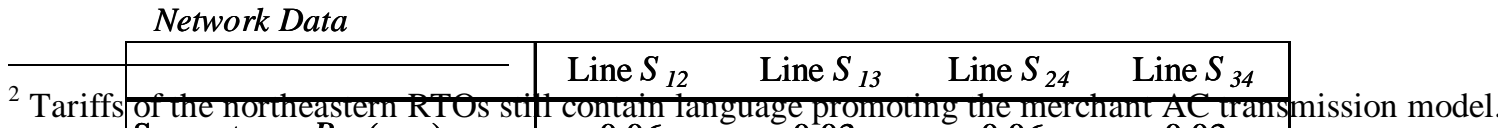

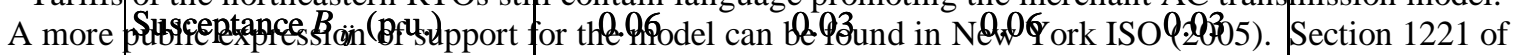

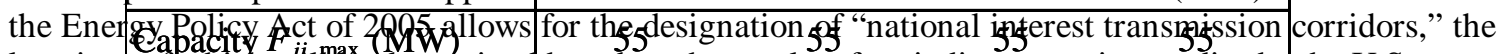

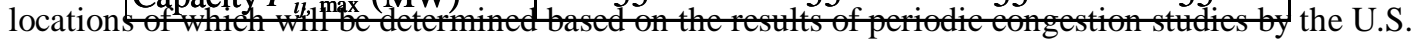

Department of Energy. See FERC Docket No. RM-06-12-000, "Regulations for Filing Applications for Permits to Site Interstate Electric Transmission Corridors."

${ }^{3}$ We express the line limits in MW since we are concerned with real power flows. Thermal and stability limits in actual networks are given in MVA, and are rated for both real and reactive power.
} 
Figure 1: Four-bus parallel test network

The cost curves of the generators are parameterized as:

$$
C_{l}\left(P_{G 1}\right)=200+10.3 P_{G 1}+0.008 P_{G 1}^{2}
$$

$$
C_{4}\left(P_{G 4}\right)=300+50 P_{G 4}+0.1 P_{G 4}^{2},
$$

where $P_{G i}$ is the real power output of the $i$ th generator.

Figure 1 shows the flow of power through the network. The locational marginal prices (LMP) derived from a lossless DC optimal power flow run on the network are all equal to $\$ 12.11 / \mathrm{MWh}$. The optimal power flow (OPF) algorithm dispatches generation assets in merit (least-cost) order subject to the physical constraints of the electric network. The problem is formulated as (Wood and Wollenberg 1996):

$$
\min _{P_{G i}, \theta_{i}, F_{i j}} C_{G 1}\left(P_{G 1}\right)+C_{G 4}\left(P_{G 4}\right)
$$

subject to the following constraints, for all $i$ and $j$ except the slack (or reference) bus:

$$
\begin{aligned}
& \sum_{i} P_{G i}=\sum_{i} P_{L i} \\
& F_{i j}=B_{i j}\left(\theta_{i}-\theta_{j}\right) \\
& P_{i}=\sum_{j} F_{i j} \\
& \left|F_{i j}\right| \leq F_{i j}^{\max } \\
& 0 \leq P_{G i} \leq P_{G i}^{\max } \\
& F_{i j}^{\max } \geq 0 .
\end{aligned}
$$

where $B_{i j}$ is the susceptance of the transmission line connecting buses $i$ and $j, F_{i j}$ is the flow of real power from bus $i$ to bus $j, P_{L i}$ is the real power demanded at bus $i, \theta_{i}$ is the voltage angle at the $i$ th bus, and $P_{i}=P_{G i}-P_{L i}$ is the net real power demanded at the $i$ th bus.

Bohn, Caramanis, and Schweppe (1984) derive optimal locational prices (also known as locational marginal prices or LMP) from the OPF formulation in equation (4). In the DC OPF with no resistive losses, the LMP at the $i$ th bus is given by (Yu, Leotard, and Ilić 1999):

$$
\pi_{i}=\lambda+\sum_{k} H_{i k} \mu_{k}
$$


where $\lambda$ is the system marginal cost of generation, $\mu_{k}$ is the shadow price of transmission along line $k$ (derived from the solution of the OPF in equation 4), and $H_{i k}$ is the $i k$ th entry of the power transfer distribution matrix:

$$
[H]_{i k}=\frac{\partial F_{k}}{\partial P_{i}}
$$

Sauer (1981) and Baldick (2003) provide an explicit formula for the entries of the distribution factor matrix under the DC power flow assumptions.

Equations (5) and (6) show that the LMP at bus $i$ represents the social marginal cost of supplying an additional unit of power at bus $i$ (Wu et. al. 1996). Thus, in the absence of generation or transmission constraints (or losses), LMPs should be equal throughout the network. This is the case for the network in Figure 1. The total cost of serving the 100 MW of demand at bus 4 is equal to $\$ 1,620$ per hour.

Next, suppose that a fifth transmission line was added to the network in Figure 1, connecting buses 2 and 3. This transforms the network from a simple parallel network to a meshed network consisting of two back-to-back triangles, as shown in Figure 2. The results of the DC OPF in equation (3) run on this modified network are also shown in Figure 2. The generator cost curves and other network parameters are identical to the network in Figure 1.

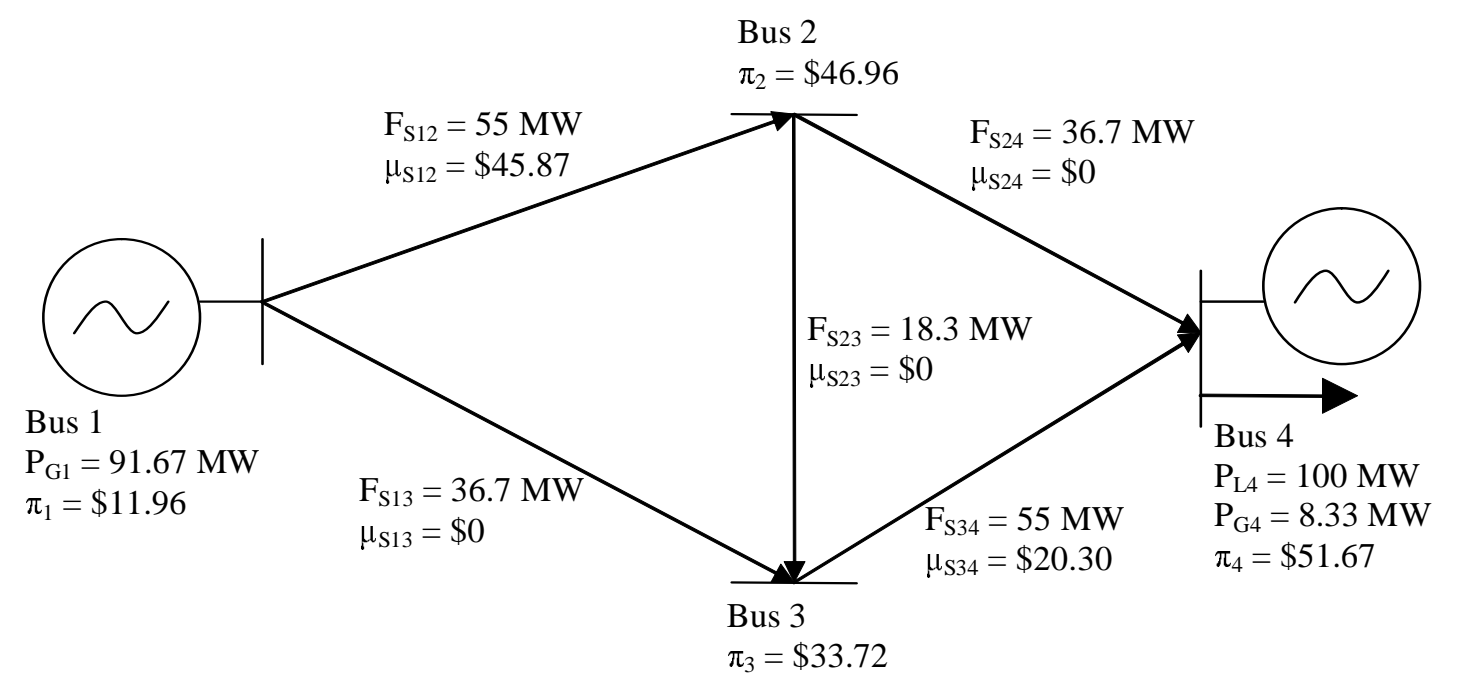

Figure 2: Four-bus Wheatstone test network.

As can be seen from Figure 2, adding the link between buses 2 and 3 causes congestion in the network. Lines $S_{12}$ and $S_{34}$ hit their rated limit of $55 \mathrm{MW}$. The remaining two lines on the boundary of the network (lines $S_{13}$ and $S_{24}$ ) each carry $36.7 \mathrm{MW}$. The congestion in the network implies that the generator at bus 1 can no longer supply all $100 \mathrm{MW}$ demanded by the load at bus 4; generator 1 only produces $91.67 \mathrm{MW}$. The remainder is 
made up with the more-expensive generator at bus 4, which produces $8.33 \mathrm{MW}$ of power (in the absence of a generator at bus 4, blackouts totaling 8.33 MW would occur in the network). This increases the total cost of serving the load to $\$ 1,945$ per hour.

The network topology shown in Figure 2 is known as the Wheatstone network, and the link between buses 2 and 3 is known as the Wheatstone bridge. ${ }^{4}$ The phenomenon that adding links to a network can actually cause congestion is known as the Braess Paradox. This behavior was first formalized outside of electric circuits by Braess (1968) in the context of automotive highway networks, but has been discovered to occur in a variety of other type of networks. Korilis, Lazar, and Orda $(1997,1999)$ examine the Braess Paradox in the context of internet routing, while Calvert and Keady (1993) and Bean, Kelly, and Taylor (1997) discuss the Paradox for more general networks, including telecommunications and pipes. Arnott and Small (1994) discuss an actual example of the Braess Paradox in a German road network.

\section{The Relationship Between Congestion and Reliability in the Four-Bus Wheatstone Test Network}

Our focus on the Wheatstone configuration is motivated in part by Duffin (1965) and Milchtaich (2005), who demonstrate that any network topology can be decomposed into purely series-parallel components and components containing an embedded Wheatstone sub-network. Although it is possible for a simple series-parallel power network to exhibit Braess' Paradox, ${ }^{5}$ congested Wheatstone networks have a number of other properties of interest, as described in Blumsack (2006a Ch. 3 and 4):

1. The Wheatstone bridge causes congestion in other parts of the network, but the bridge itself does not become congested. Relieving congestion in the Wheatstone network requires either upgrading both congested lines, or removing the Wheatstone bridge from the system.

2. Both congested lines sport non-negative shadow prices in the DC OPF model. ${ }^{6}$ Financially, each of these shadow prices individually does not represent the social value of incremental transmission upgrades. The sum of the two shadow prices does represent the social value of incremental upgrades on both congested lines.

3. The use of shadow prices or LMPs to guide network expansion would lead transmission companies or system planners to upgrade both congested lines. However, removing the Wheatstone bridge would accomplish the same goals, perhaps at a lower cost.

4. In a system with non-utility or "merchant" transmission, the Wheatstone network represents a case where investors could earn profits by building lines that cause

\footnotetext{
${ }^{4}$ The earliest known reference, given in Ekelöf (2001), is Charles Wheatstone's 1843 article, "An Account of Several New Instruments and Processes for Determining the Constants of a Voltaic Circuit," Philos. Trans. R. Soc. Pt. II, pp. 303 - 327. Ekelöf's interesting history notes that Wheatstone did not actually invent the circuit configuration.

${ }^{5}$ Milchtaich's paper builds on Duffin's result by proving that for a large class of undirected networks, the existence of an embedded Wheatstone sub-network is a necessary and sufficient condition for the network to display the Braess Paradox. This result does not apply to power networks (Blumsack 2006, Ch. 3).

${ }^{6}$ This may not be true in the AC optimal power flow model.
} 
congestion, even if congestion rights are allocated according to the "feasibility allocation rule" described in Hogan (1992) and Bushnell and Stoft (1996).

Despite the negative effects on the system, the Wheatstone bridge may be justified on reliability grounds. Consider the Wheatstone network shown in Figure 2, except suppose that lines $S_{24}$ and $S_{34}$ can carry $100 \mathrm{MW}$. Without the Wheatstone bridge, an outage on either line $S_{24}$ or $S_{34}$ will restrict the power transfer to $55 \mathrm{MW}$ between buses 1 and 4 . Thus, for a load of $100 \mathrm{MW}$ at bus 4 , the expensive generator at bus 4 must generate 45 MW in order to avoid shedding any load. This increases the cost of operating the network according to the differences in marginal costs of the two generators. If the Wheatstone bridge is installed in the network, the power transfer between buses 1 and 4 in event of an outage across line $S_{24}$ or $S_{34}$, is $100 \mathrm{MW}$, and the load can continue to be served with the inexpensive generator at bus 1 .

During normal system operations, the Wheatstone bridge imposes a cost on the system in the form of congestion. In the case of a contingency on line $S_{24}$ or $S_{34}$ the Wheatstone bridge offers a reliability benefit to the system. Specifically, the Wheatstone bridge serves to satisfy the $N-1$ reliability criterion with respect to transmission lines. The unserved energy expectation and probability also fall accordingly. Increased reliability is earned at the cost of increased congestion. The only exception to this tradeoff occurs at very low levels of demand - less than $55 \mathrm{MW}$ in the case of the Wheatstone network in Figure 2. Thus, the value of the Wheatstone bridge is the difference between the reliability benefit that it offers to the system over some period of time and the congestion costs it imposes on the system.

In the Wheatstone network, the extent of the tradeoff is a function of the level of demand and the probability of an outage on the lines downstream of the Wheatstone bridge. Conditional on an outage on either line $S_{24}$ or $S_{34}$, let $T_{W}$ be the feasible transfer capacity between buses 1 and 4 and let $T_{0}$ be the feasible transfer capacity between buses 1 and 4 without the Wheatstone bridge. ${ }^{7}$ Define $U$ to be the event of an outage on line $S_{24}$ or $S_{34}$. $U$ is assumed to be a Bernoulli random variable that is equal to one (the case of an outage) with probability $u$, and equal to zero (no outage) with probability $1-u$. The level of demand at bus $4, P_{L A}$, is assumed to be constant or perfectly predictable.

\subsection{Congestion and Reliability Metrics}

We measure the congestion cost imposed on a system with $N B$ buses during normal operations by the difference in total cost of serving a given demand profile $\left\{P_{L 1}^{*}, \ldots, P_{L, N B}^{*}\right\}$ with the Wheatstone bridge in the network, and the total cost of serving an identical demand profile without the Wheatstone bridge. With the Wheatstone bridge, suppose that the generation profile of the network is $\left\{P_{G 1}^{*}, \ldots, P_{G, N B}^{*}\right\}$ and that the generation profile without the Wheatstone network is $\left\{P_{G 1}^{\prime}, \ldots, P_{G, N B}^{\prime}\right\}$. The congestion cost associated with the Wheatstone can be written as:

\footnotetext{
7 "Feasible transfer capacity" means the total amount of power that can be transferred from bus 1 to bus 4 while respecting all network constraints.
} 


$$
C C=\sum_{i=1}^{N B}\left(C_{i}\left(P_{G i}^{*}\right)-C_{i}\left(P_{G i}^{\prime}\right)\right)
$$

In the case of the Wheatstone network in Figure 2, we have $C C \geq 0$, but in theory this need not necessarily hold in more general networks.

Quantifying the reliability benefit of the Wheatstone network involves comparing the amount of unserved energy in a network equipped with a Wheatstone bridge to the amount of unserved energy in a network without the Wheatstone bridge:

(6) $U E=\left\{\begin{array}{l}T_{W}-T_{0}, \quad U=1 \\ 0, \quad U=0\end{array}\right.$.

Note that $U E$ measures only the decrease in unserved energy associated with the Wheatstone bridge. In the case of the Wheatstone network shown in Figure 2, we will have $U E \geq 0$ if the generator at bus 4 has a maximum output of less than $45 \mathrm{MW}$.

Following Bohn, Caramanis, and Schweppe (1984) and Joskow and Tirole (2006), enduse consumption at the $i$ th bus is assumed to follow a demand function $\pi_{i}\left(P_{L i}\right)$, where $\pi_{i}$ is the price faced by consumers at bus $i$. Consumer surplus at the $i$ th bus is therefore given by the value function:

$$
v_{i}\left(\overline{P_{L i}}\right)=\int_{0}^{\overline{P_{L i}}} \pi_{i}\left(P_{L i}\right) d P_{L i} .
$$

The cost (to consumers) of an amount of unserved energy $T_{W}-T_{0}$ is:

$$
C U E=U \times\left(v\left(T_{W}\right)-v\left(T_{0}\right)\right)
$$

If there is no outage on the line, then $U E=0$ and thus $C U E=0$. Also, if $T_{W}=T_{0}$ (that is, the possible transfer across the network is not affected by line outages or the presence of the Wheatstone bridge), then the cost of unserved energy is also zero. Assuming that the outage probability is independent of the level of demand, we measure system reliability using the expected cost of unserved energy:

$$
E C U E=u \times\left(v\left(T_{W}\right)-v\left(T_{0}\right)\right) .
$$

The (expected) net benefit of the Wheatstone bridge in the presence of nonstochastic demand is thus $E(N B)=E C U E-(1-u) C C$.

\subsection{Application to the Four-Bus Test Network}


Applying the cost-benefit calculus of equations (5) through (9) to the four-bus Wheatstone network in Figure 2 is straightforward. For $P_{L 4}$ between $0 \mathrm{MW}$ and 100 MW, we simulate generation dispatch and power flows in the network both with and without the Wheatstone bridge; and with and without a contingency on one of the transmission lines forming the boundary of the network.

For ease of illustration, we make the following simplifying assumptions:

1. The $100 \mathrm{MW}$ of load at bus 4 represents net demand. This modifies the network in Figure 2 by effectively removing the generator at bus 4 .

2. Outages occur in the downstream portion of the network; that is, on either line $S_{24}$ or line $S_{23}$.

3. Each line outage lasts one period. Thus, the net benefit of the Wheatstone bridge is in terms of dollars per MW-interrupted.

4. The consumer's per-period marginal value function is constant at $\$ 50 / \mathrm{MW}$. We will call this the value of lost load (VOLL).

We can thus write equation (8) as:

$$
C U E=U \times\left(V O L L \times T_{W}-V O L L \times T_{0}\right) .
$$

The net benefit of the Wheatstone bridge is calculated using the simulation output as:

$$
E(N B)=\underbrace{u \times\left(V O L L \times T_{W}-V O L L \times T_{0}\right)}_{\text {reliabilit y }}-\underbrace{(1-u) \sum_{i=1}^{N B}\left(C_{i}\left(P_{G i}{ }^{*}\right)-C_{i}\left(P_{G i}{ }^{\prime}\right)\right)}_{\text {congestion }} .
$$

In our simulations, we assume that there is a system operator who dispatches generating resources to solve the following optimization problem:

$$
\min _{P_{L i}, P_{G i}} \sum_{i}\left(C_{i}\left(P_{G i}\right)+V O L L_{i} \times U E_{i}\right)
$$

s.t.

(11a) $\quad \sum_{j} F_{i j}^{\text {transfer }}=P_{G i}-P_{L i} \quad \forall i$

(11b) $\mathbf{g}(\mathbf{x})=\mathbf{0}$

(11c) $\quad \mathbf{h}(\mathbf{x}) \leq \mathbf{0}$

where $\mathbf{g}(\mathbf{x})$ and $\mathbf{h}(\mathbf{x})$ represent the equality and inequality constraints in the optimal power flow problem, as expressed in equation (3). The term $\sum_{j} F_{i j}^{\text {transfer }}$ represents the total 
amount of power than can be transferred into or out of the $i$ th bus. ${ }^{8}$ Thus, constraint (11c) represents the power balance condition.

Equation (10) provides some insight as to how the net benefit function is expected to behave. For sufficiently low levels of demand, the congestion cost will be zero since the rated megawatt limit of the lines in the network is large relative to demand. Similarly, the reliability benefit of the Wheatstone will also be zero if demand is low relative to the amount of capacity in the network. In this case, even if a line goes out and the network does not have a Wheatstone bridge to redirect flows, outages will not occur in the downstream portion of the Wheatstone (bus 4 in the case of Figure 2).

The simulation results are displayed graphically in Figure 3. In calculating the net benefit function in equation (10), we consider outage probabilities between $1 \times 10^{-6}$ and $1 \times 10^{-3}$. The cost function of the generator at bus 1 is given in equation (1).

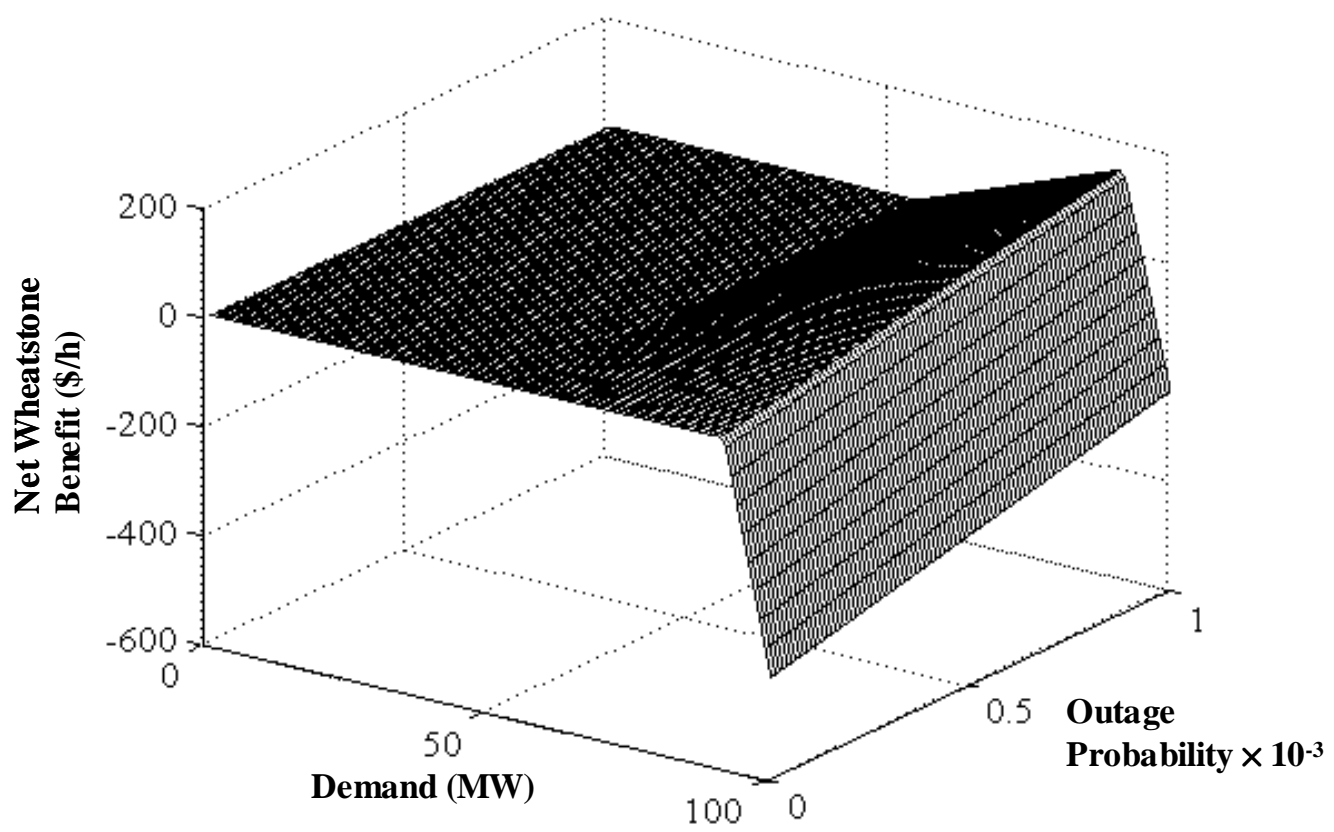

Figure 3: Expected net benefit of the Wheatstone bridge in the four-bus test network.

\section{Application to the IEEE 118-bus Network}

The four-bus test network from Section 3 is useful for illustrating the concepts behind equations (5) through (10), but is not a very descriptive model of an actual system. A Wheatstone network embedded in a larger system might have net generation or load at all four buses; generation or load at one end of the Wheatstone bridge could sufficiently alter

\footnotetext{
${ }^{8}$ Transfer capacity out of a given bus is constrained by the amount of available generation and transmission. Transfer capacity into a given bus (or other area of a power network) depends on the supply/demand balance in other portions of the network. We take the total transfer capacity as exogenous. Wood and Wollenberg (1996) discuss the calculation of marginal and total transfer capacity.
} 
the pattern of flows such that congestion is avoided. The reliability benefit of the Wheatstone bridge also depends on how it interacts with the rest of the network; the loss of one of the boundary links might simply be made up by increased flows from other portions of the network, with the Wheatstone bridge not adding any benefit to the system at all.

Equations (5) through (10) decompose the congestion attribute of a given transmission upgrade from its effect on reliability. Blumsack, Ilić, and Lave (2006) derive explicit topological conditions under which the addition of a new transmission line will decrease congestion, but will not improve reliability (and vice versa). In particular, they show that reliability and congestion can represent tradeoffs only if the network has an embedded Wheatstone sub-network. Blumsack (2006b) provides a graph-theoretic algorithm for identifying embedded Wheatstone structures in larger networks.

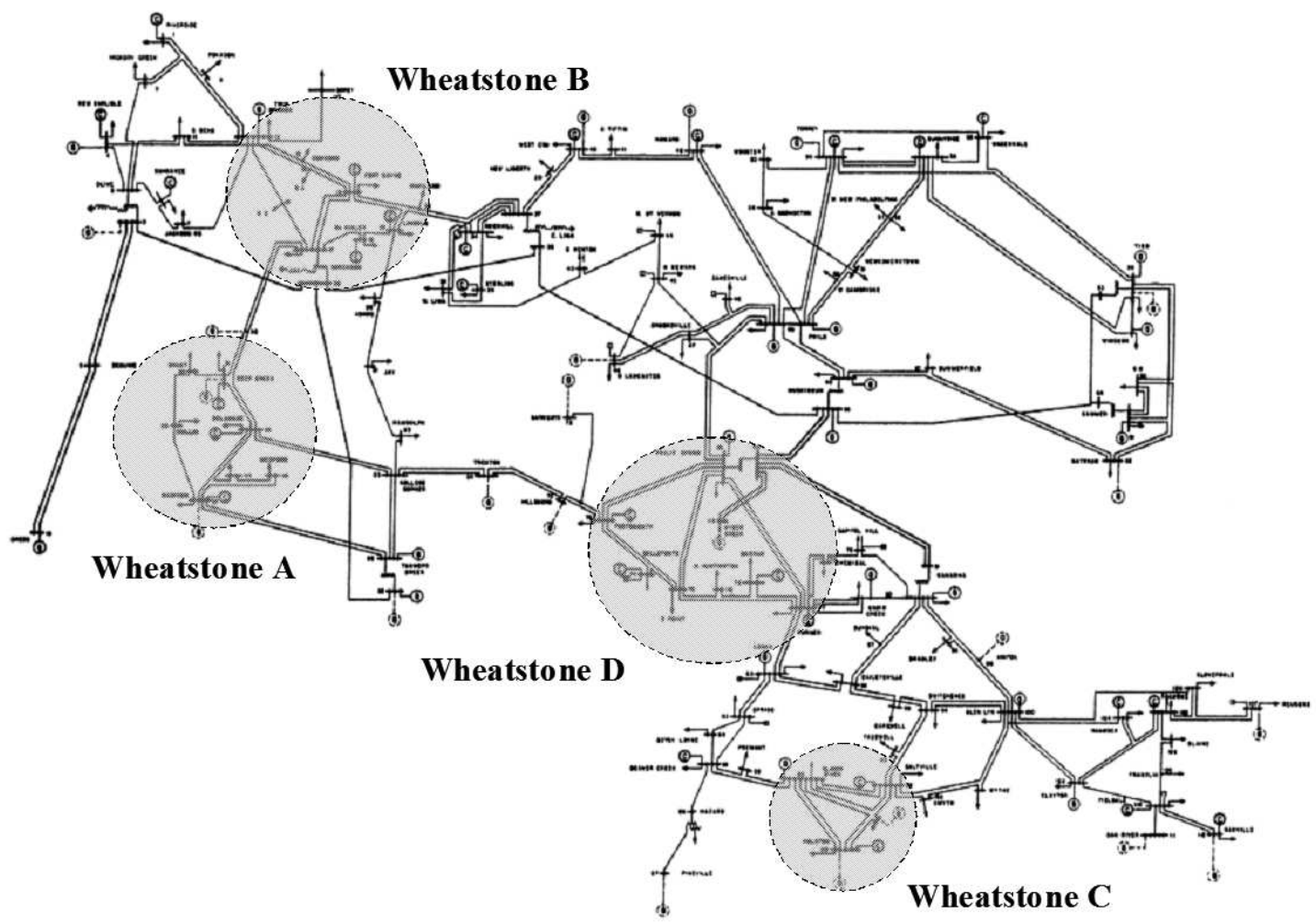

Figure 4: Four Wheatstone sub-networks of the IEEE 118-bus test network.

The magnitude of the relationship between congestion and reliability is ultimately an empirical question. We examine the congestion and reliability effects of four Wheatstone sub-networks in the IEEE 118-bus test network, using the same simulation procedure as in Section 3. The four Wheatstone sub-networks are indicated in Figure 4, which also 
shows the topology of the 118-bus network. ${ }^{9}$ The networks are labeled A, B, C, and D. The system topologies for the four networks and illustrative base case power flows are shown Table 1, for comparison with the four-bus Wheatstone test network of Figure $3 .^{10}$ The base-case power flows are used to determine "upstream" and "downstream" portions of each embedded Wheatstone sub-network, as described below. ${ }^{11}$

For each level of demand in each Wheatstone sub-network, the associated congestion cost is measured using equation (5). Thus, the congestion cost is defined to be the difference in total system cost to serve identical demand profiles in a system with the Wheatstone bridge and without the Wheatstone bridge.

\begin{tabular}{|c|c|llll|}
\hline \multicolumn{2}{|c|}{} & \multicolumn{4}{|c|}{ Wheatstone Sub-Network } \\
\hline \multirow{2}{*}{$\mathrm{S}_{12}$} & A & B & C & D \\
& Reactance (p.u.) & 0.09 & 0.02 & 0.12 & 0.13 \\
& Base-Case Flow (MW) & 27 & 13 & 220 & 104 \\
\hline \multirow{2}{*}{$\mathrm{S}_{13}$} & Reactance & 0.12 & 0.02 & 0.05 & 0.14 \\
& Base-Case Flow & 23 & 2 & 186 & 33 \\
\hline \multirow{2}{*}{$\mathrm{S}_{24}$} & Reactance & 0.09 & 0.05 & 0.05 & 0.1 \\
& Base-Case Flow & 32 & 92 & 121 & 210 \\
\hline \multirow{2}{*}{$\mathrm{S}_{34}$} & Reactance & 0.07 & 0.01 & 0.05 & 0.19 \\
& Base-Case Flow & 15 & 25 & 257 & 19 \\
\hline \multirow{2}{*}{$\mathrm{S}_{23}$} & Reactance & 0.09 & 0.04 & 0.05 & 0.12 \\
& Base-Case Flow & 35 & 118 & 151 & 140 \\
\hline
\end{tabular}

Table 1: Topology and base-case power flows in four Wheatstone sub-networks embedded in the IEEE 118-bus test system.

The reliability benefit of the Wheatstone bridge is measured using equations (8) and (9). We assume that the marginal value of consuming power is constant, and that all consumers in the network have an identical value function $v_{i}\left(P_{L i}\right)$. In this set of simulations, we set the value of lost load equal to $\$ 1,000 / \mathrm{MW}$-interrupted. The analysis considers a range of outage probabilities between $10^{-7}$ and $10^{-1}$, so the $(1-u)$ term in equation (10) is never large. ${ }^{12}$

\footnotetext{
${ }^{9}$ Data for the test network were downloaded from the IEEE Power Systems Test Case Archive at http://www.ee.washington.edu/research/pstca/.

${ }^{10}$ One-line diagrams illustrating the base-case power flow results can be found in Blumsack (2006a, Ch.6)

${ }^{11}$ Depending on supply and demand conditions throughout the network, it is theoretically possible that the "upstream" and "downstream" portions could change. We did not encounter this phenomenon in the simulations performed for this paper.

${ }^{12}$ Larger outage probabilities were examined but are not included here. Once the outage probability becomes much larger than $10 \%(u=0.1)$, at larger levels of demand, both the congestion cost and
} 
Calculating the net benefit function in equation (10) requires running four sets of optimal power flows on the IEEE 118-bus network for each of the four Wheatstone sub-networks under consideration. The DC optimal power flow model in equations (11) is used throughout this analysis. The four power-flow cases are:

Case I: The "base case" set of DC optimal power flows, where the sub-network has the Wheatstone bridge, and there is no assumed contingency on any of the transmission lines.

Case II: Same as Case I, but the DC optimal power flows are run on the sub-network without the Wheatstone bridge.

Case III: This case assumes an outage on one of the boundary links in the Wheatstone sub-network, but assumes the sub-network has a Wheatstone bridge.

Case IV: An outage is assumed on one of the links, and there is no Wheatstone bridge in the sub-network.

The power-flow results from Cases I and II are used to calculate the congestion effect of the Wheatstone bridge, and the results from Cases III and IV are used to calculate the reliability effect of the Wheatstone bridge.

Wheatstone sub-networks $\mathrm{C}$ and D are good examples of our simulation results, so we discuss those in greater detail than Wheatstone sub-networks A and B. The full set of results from simulations run on all four sub-networks are in Blumsack (2006a, Ch.6).

\subsection{Cost-Benefit Analysis of Wheatstone $\mathrm{C}$}

Wheatstone sub-network $C$ is located in the southeastern portion of the IEEE 118-bus network, as shown in Figure 4. This Wheatstone has two of its four component buses connected to the external network. From Table 1, we see that power flows from the external network through the Wheatstone network towards bus 90 . Thus, bus 90 is designated as the downstream node for this sub-network.

Figures 5 and 6 show the congestion cost and reliability benefit of the bridge in Wheatstone C. The real power demand at bus 90 is assumed to vary between 0 and 500 MW; we hold demand constant at all other nodes in the network. The positive value for the congestion cost indicates congestion charges associated with the Wheatstone bridge. At lower levels of demand, Figure 5 shows that the congestion caused by the Wheatstone bridge increases with the level of demand, just as in the four-bus test network shown in Figure 3. At demand levels larger than $450 \mathrm{MW}$, generation from elsewhere in the network is dispatched to meet the increased load at bus 90 , and the congestion cost associated with the Wheatstone bridge declines. The expected congestion cost does not vary widely with the outage probability because we only consider small outage probabilities (less than a 10\% chance of an outage).

reliability benefit get large enough so as to obscure the behavior of the net benefit function at lower levels of demand. 


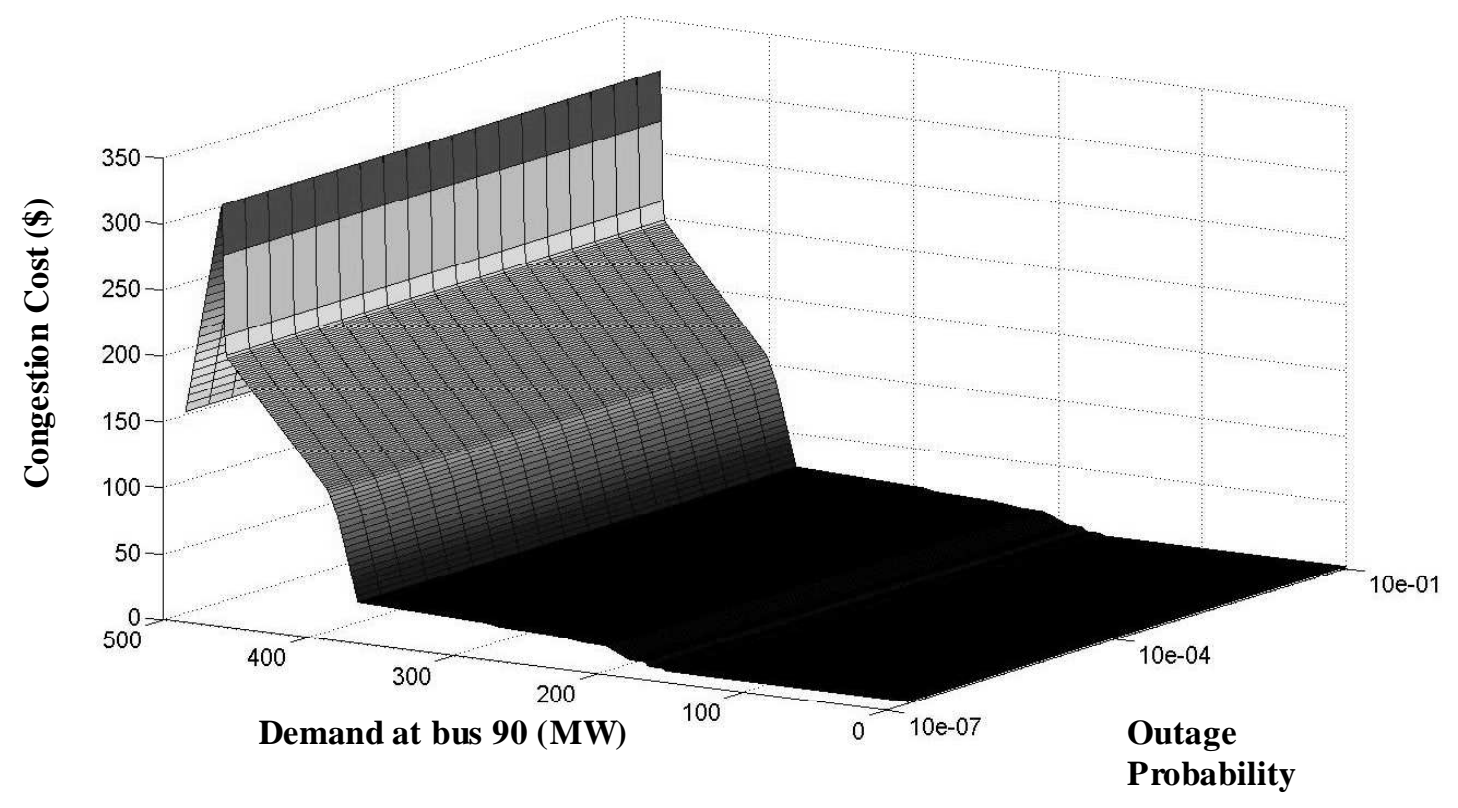

Figure 5: Expected congestion cost associated with the bridge in Wheatstone $C$.

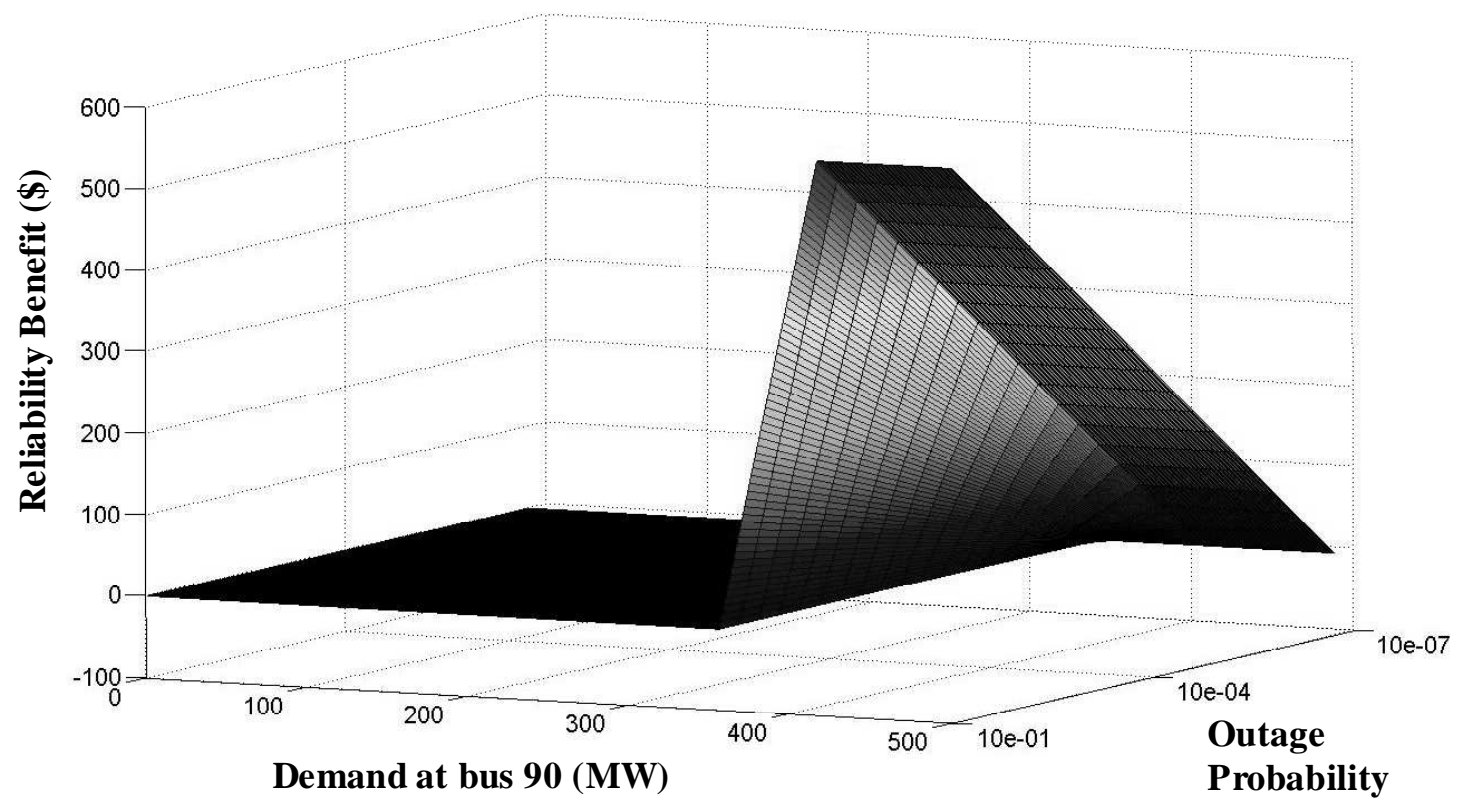

Figure 6: Expected reliability benefit associated with the bridge in Wheatstone $C$.

The reliability benefit associated with the Wheatstone bridge is shown in Figure 6. At low levels of demand, the capacity in Wheatstone sub-network $\mathrm{C}$ is large relative to demand, so a single line outage makes little difference in the ability of power to be 
transferred across the network towards bus 27. At larger levels of demand, the expected reliability benefit is highly sensitive to both the level of demand and the outage probability.

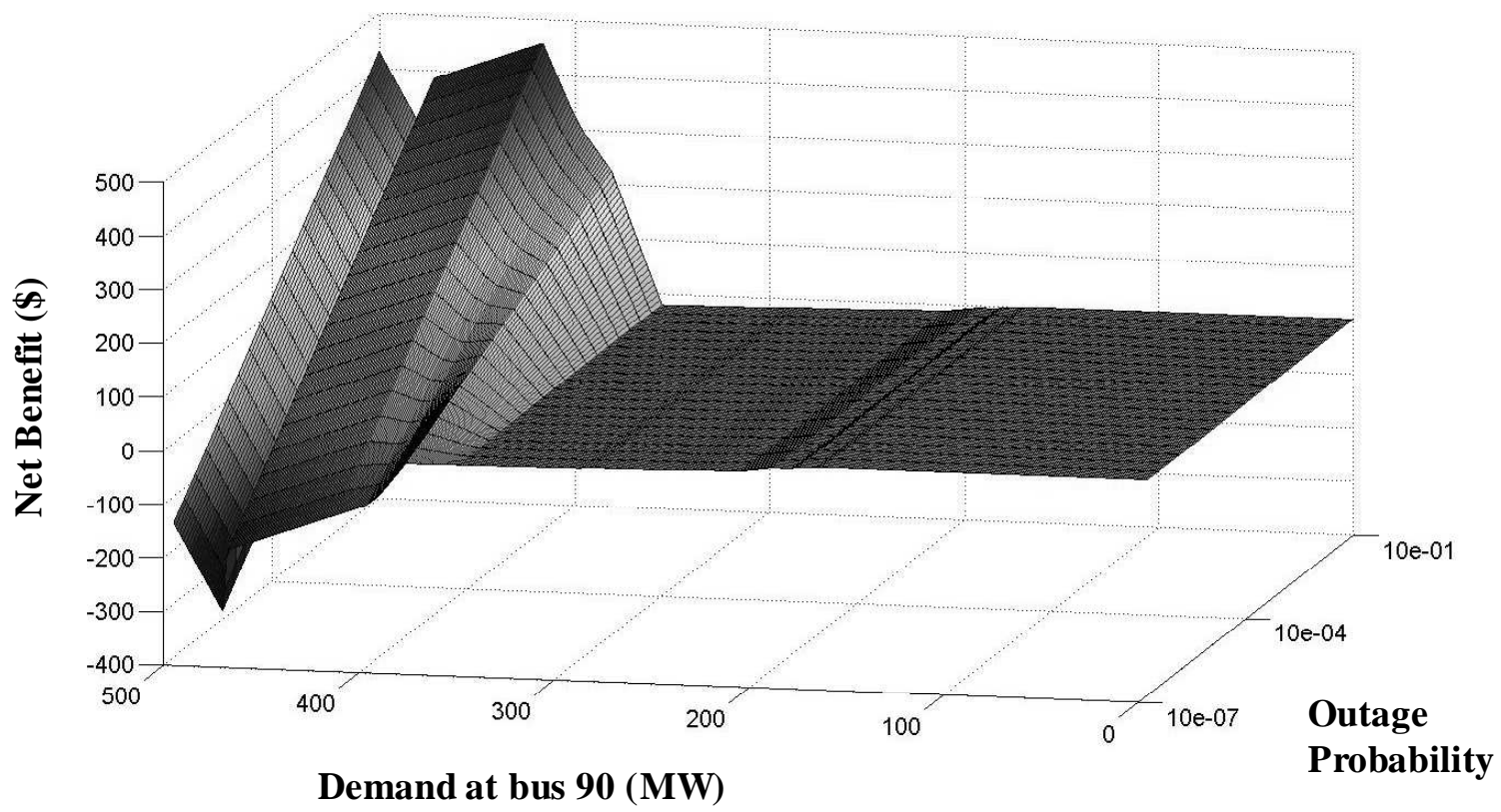

Figure 7: Expected net benefit associated with the bridge in Wheatstone C.

The net benefit of the bridge in Wheatstone sub-network $C$ is shown in Figure 7. An instructive comparison can be made between the behavior of Wheatstone $\mathrm{C}$ and the fourbus test network discussed in Section 2. In Wheatstone $\mathrm{C}$, congestion and reliability are only independent for low levels of demand (150 MW or less). For this range of demand, the Wheatstone imposes a congestion cost while the reliability benefit is zero. Only at higher levels of demand does the net benefit function indicate the tradeoff between the congestion cost imposed by the Wheatstone bridge and its reliability benefit. Once the reliability benefit kicks in, the net benefit function will rise more sharply if the probability of an outage is larger; for low outage probabilities, the congestion component of the net benefit function dominates.

\subsection{Cost-Benefit Analysis of Wheatstone D}

The second Wheatstone sub-network discussed here is located in the middle of the IEEE 118-bus network, just northwest of Wheatstone C. Topologically, Wheatstone D appears to be more of an interior Wheatstone than the other three sub-networks, as it is located near some of the system's larger and less expensive generating units located at buses 80 and 65 . The congestion and reliability properties of this sub-network should be different than the other three Wheatstone sub-networks. The base-case power flow run on this Wheatstone sub-network indicates that bus 77 should be considered the downstream bus; power flows from the external network through the Wheatstone towards bus 77. 


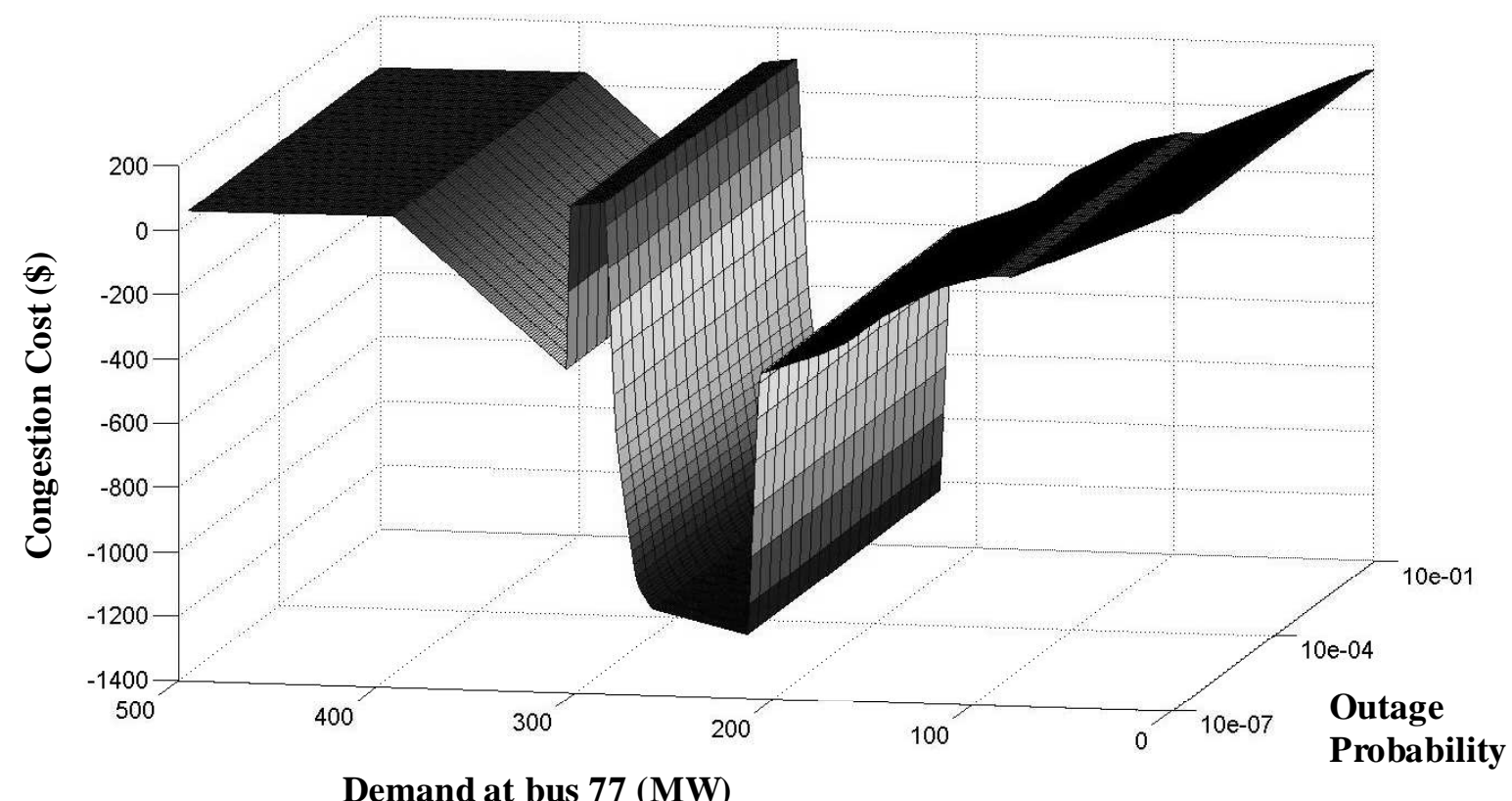

Figure 8: Expected congestion cost associated with the bridge in Wheatstone D.

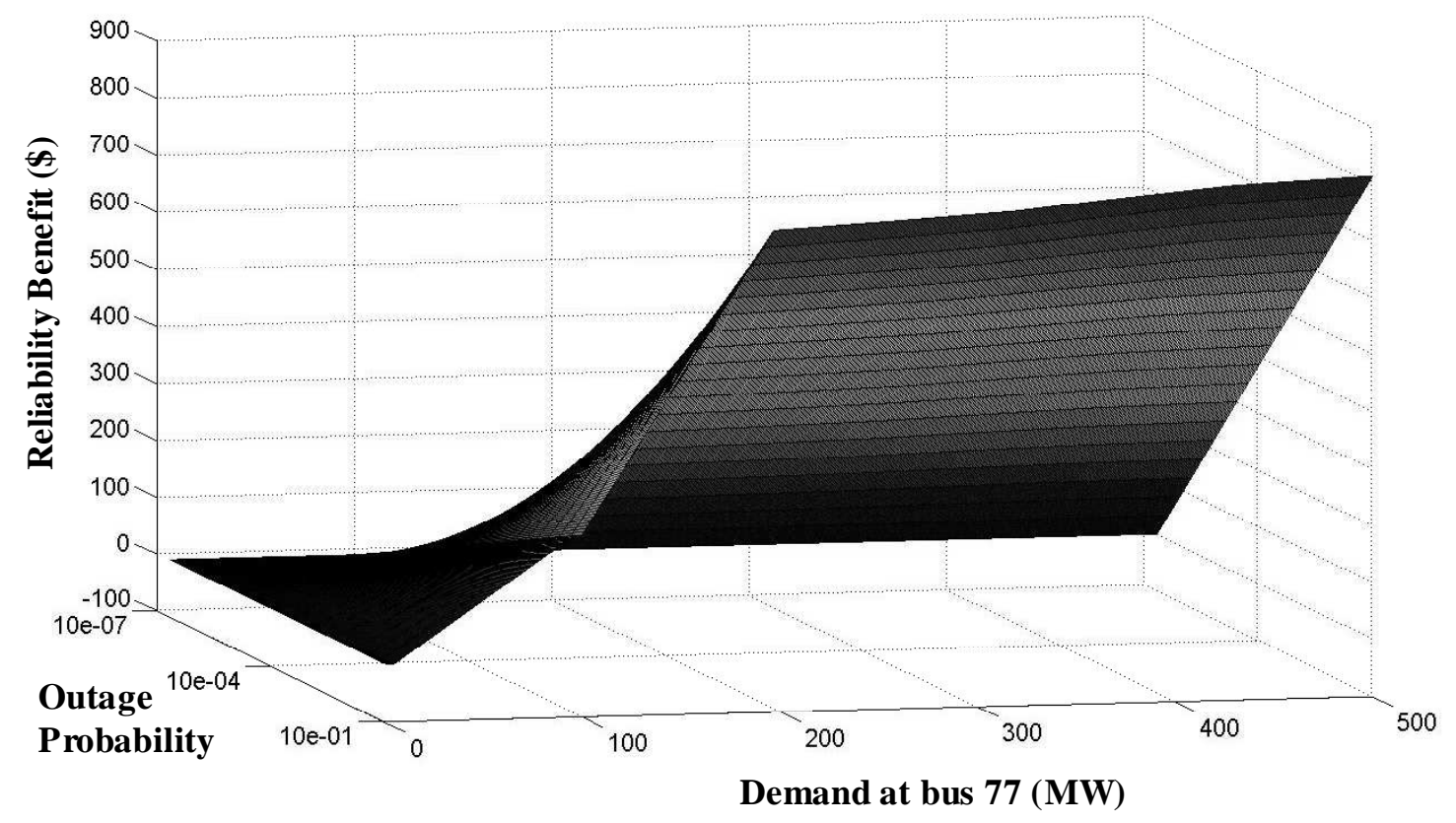

Figure 9: Expected reliability benefit associated with the bridge in Wheatstone D.

Figures 8 and 9 show the congestion cost and reliability benefit associated with the Wheatstone bridge in sub-network D. The tradeoff between congestion and reliability evident in Wheatstone sub-networks A, B, and C is not as evident. In the other three sub- 
networks discussed here, the congestion cost rises (more or less) monotonically with demand. However, Figure 8 shows the congestion cost rising and falling in a rollercoaster pattern. For the most part, the Wheatstone bridge in sub-network D has negative congestion costs, meaning that the presence of the bridge reduces congestion rather than causes congestion. The reliability benefit associated with the Wheatstone bridge in subnetwork D, as a function of demand and the outage probability, behaves similarly to the other three Wheatstone sub-networks.

The same roller-coaster pattern of the net benefit function can be seen in Figure 10, which shows the total net benefit function as both demand at bus 77 and the outage probability vary. The shape of the total net benefit function is nearly identical to the shape of the congestion cost curve in Figure 8. We conclude from Figures 8 through 10 that congestion and reliability are not independent in Wheatstone D, but neither do they represent tradeoffs. In this case, congestion and reliability are complementary. The Wheatstone bridge could be justified for reliability reasons, but (over a large range of demand) congestion would decrease as well.

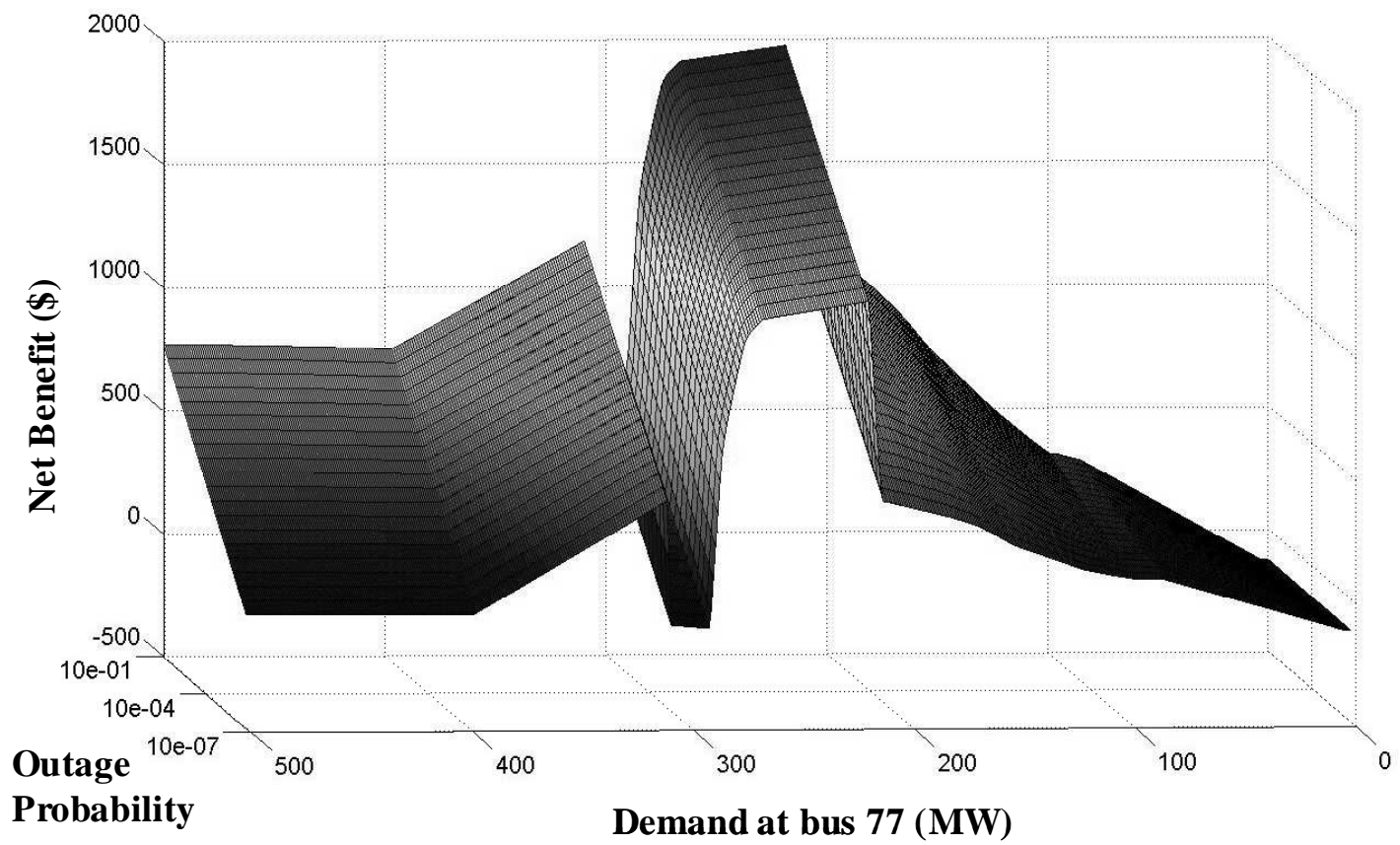

Figure 10: Expected net benefit associated with the bridge in Wheatstone D.

For a given level of the outage probability, the net benefit of the Wheatstone bridge should be an increasing function of the level of demand. Wheatstones $\mathrm{A}$ and $\mathrm{C}$ both behave this way, but the relationship is somewhat less clear for Wheatstone B and is virtually nonexistent for Wheatstone $\mathrm{D}$. This highlights the influence of the system, and the importance of location, on a given individual Wheatstone sub-network. Wheatstone sub-networks $\mathrm{A}$ and $\mathrm{C}$ are located topologically further away from the center of the 118bus network. More importantly, Wheatstones $\mathrm{A}$ and $\mathrm{C}$ have fewer connections to the 
external network. Thus, the external network has less influence over the behavior of Wheatstones A and C than over the behavior of Wheatstones B and D.

The most significant portion of the external network in explaining the behavior of Wheatstones $\mathrm{D}$ is the location of large and inexpensive generation in close proximity. Generators at buses 80 and 65 are directly connected to Wheatstone sub-network D; the generator at bus 80 is directly connected to the downstream load bus of Wheatstone D. Empirically, we found that changes in the dispatch of generator 65 had the greatest influence on the congestion-cost function shown in Figure 11. To illustrate the influence of these generators on the congestion cost and reliability benefit associated with the Wheatstone bridge in sub-network $\mathrm{D}$, we artificially increased the marginal cost of the generator at bus 65 by a factor of ten, from $\$ 2.5 / \mathrm{MWh}$ to $\$ 25 / \mathrm{MWh}$. The new net benefit, after the cost increase, is shown in Figure 11. After increasing the marginal costs of the generator at bus 65 to the point where it no longer changes dispatch in response to changes in demand at bus 77, the Wheatstone net benefit function looks much like the net benefit functions from Wheatstone $\mathrm{C}$.

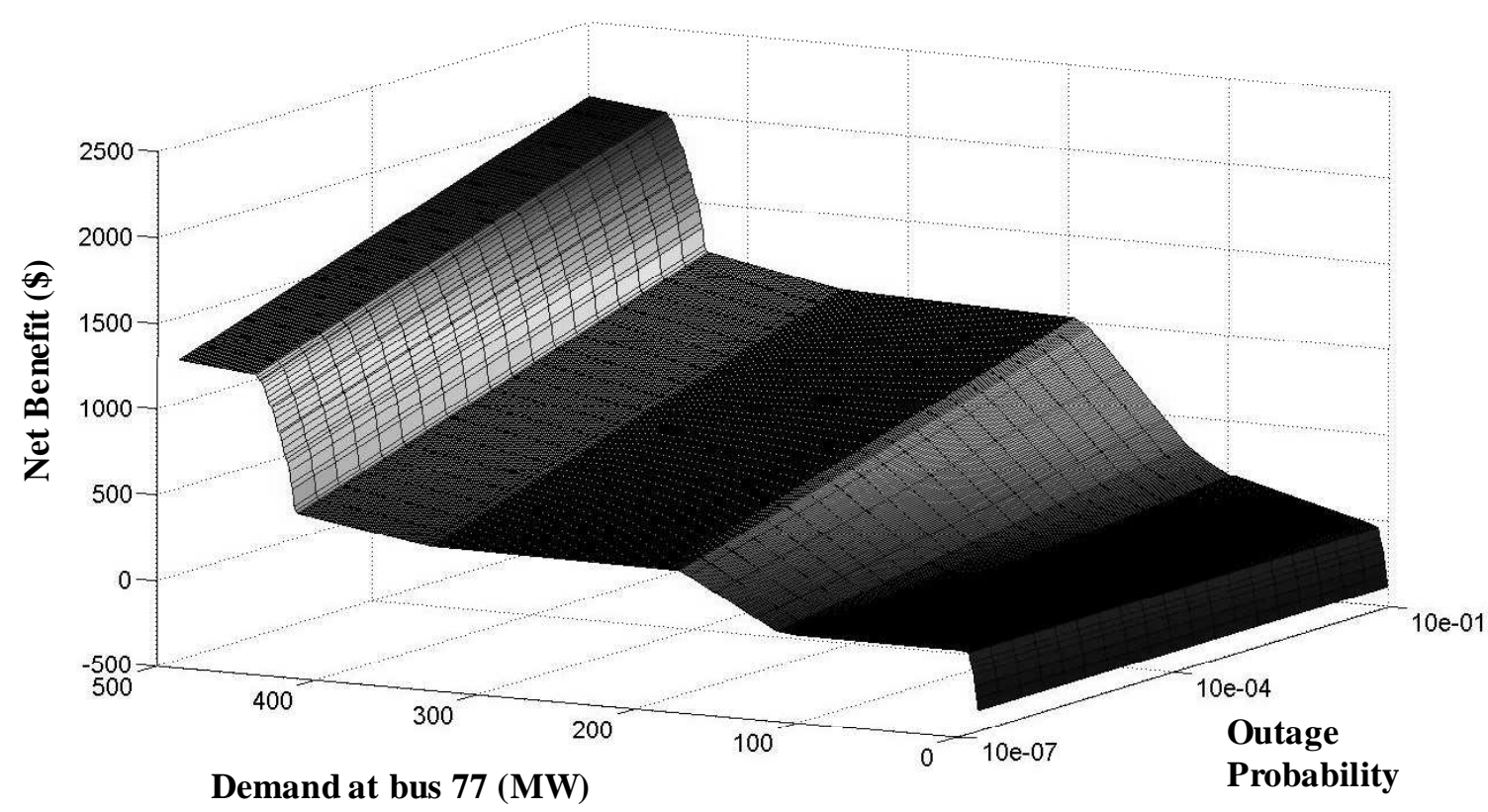

Figure 11: Expected net benefit associated with the bridge in Wheatstone D, after the marginal cost of generation has been increased at bus 65.

\subsection{Cost-Benefit Analyses of Wheatstones A and B}

The net benefit functions for Wheatstone sub-networks A and B are shown in Figures 12 and 13. Both of these sub-networks are located in the northwestern portion of the IEEE 18-bus network. Like Wheatstone $\mathrm{C}$, they are located closer to the boundary of the network; this differentiates them from Wheatstone $\mathrm{D}$, which has a more interior location. Figure 12 shows that Wheatstones A and B display the same sort of tradeoff between congestion and reliability as Wheatstone $\mathrm{C}$. 


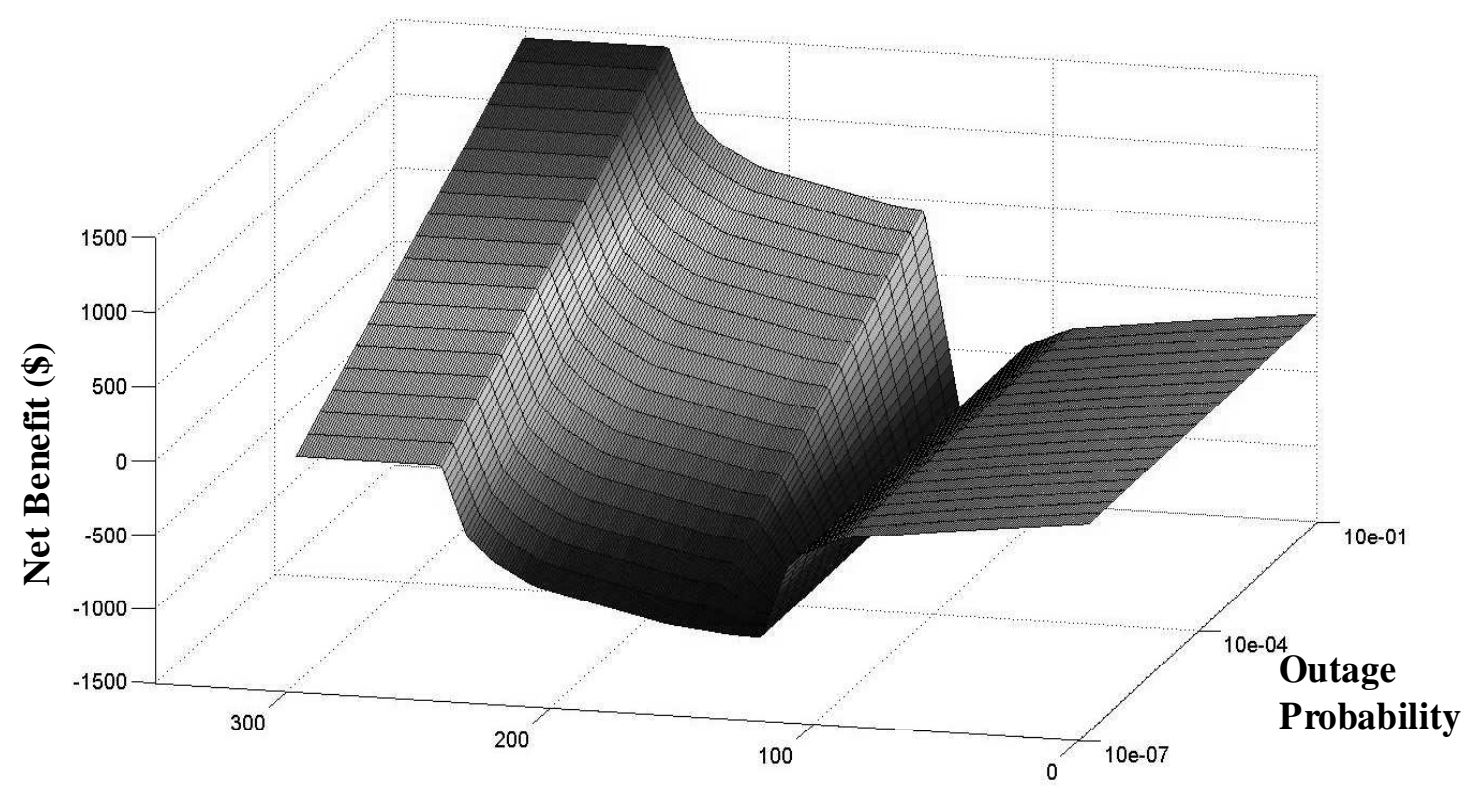

Demand at bus 27 (MW)

Figure 12: Expected net benefit associated with the bridge in Wheatstone A.

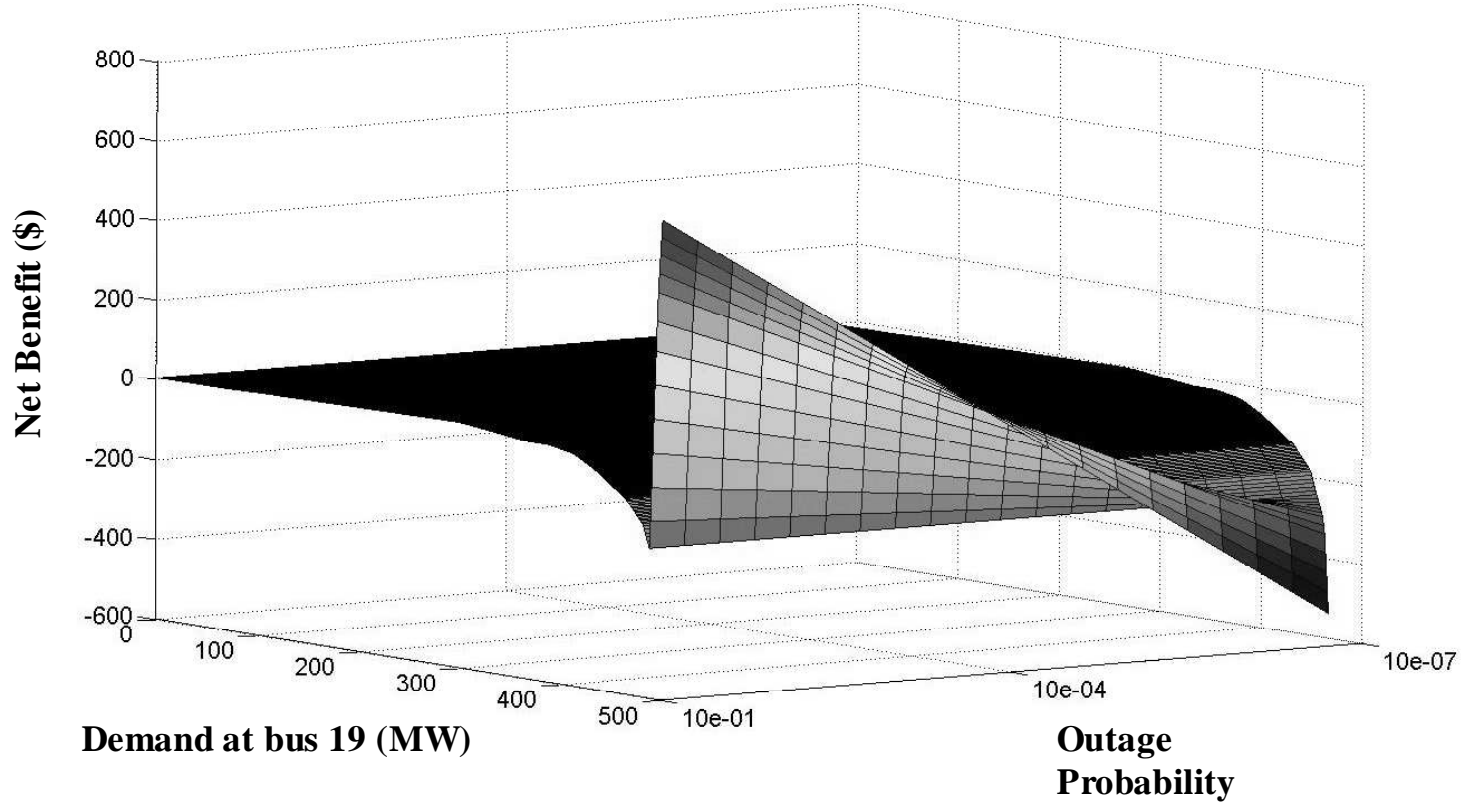


Figure 17: Expected net benefit associated with the bridge in Wheatstone B.

\section{Conclusion}

AC transmission investment is a systems problem. The nature of the problem has not changed with electric-industry restructuring, but some aspects of practice and policy have changed. In the past, most transmission investments were made with reliability and resource adequacy in mind. With the move to congestion pricing and market-based congestion management in many operating areas, and the policy focus on developing robust spot markets to support the congestion-management function of the RTO, the focus of transmission policy has changed. The job of the transmission network is not just to deliver power to customers, but is also to facilitate competition among generators. As such, the criteria for evaluating and deciding among transmission investments has shifted to emphasize the effects on competition and congestion.

Underlying this shift is an assumption that congestion and reliability are separable and independent attributes in electric networks. In this paper, we have shown that while the network attributes can be decomposed, they are rarely independent, except at levels of demand that are small relative to the capacity of the network to transfer power. Certain directed network investments, such as HVDC lines, might also be justified on economics alone, since these investments are effectively separable from the larger grid (Coxe and Ilić 1998). Whether congestion and reliability represent tradeoffs or complementary system attributes, the nature of the relationship is also dependent on the network topology and the degree to which the network is meshed. Transmission links built in simple seriesparallel networks are more likely to affect a single system attribute than are links that create Wheatstone sub-networks or other meshed structures. This observation not only clarifies the nature of the externality involved, but also suggests that academics and policymakers need to work with more sophisticated network models.

We conclude that the behavioral attributes of the four-bus standalone Wheatstone network are not universally generalizable to Wheatstone structures within larger systems. The behavior of the embedded Wheatstone networks in the 118-bus system is influenced by their location, electrical proximity to nearby network resources (that is, relative impedances), and by the initial topology of the network as a whole. We find that Wheatstone sub-networks located in more densely-connected portions of the network are more likely to be influenced by variations in adjacent load and generation. One possible implication for the planning process is that locating a Wheatstone in the middle of a meshed network and near large sources of inexpensive generation is unlikely to cause major congestion problems that would exist if the same Wheatstone were placed at the boundary of the network.

The key to analyzing general network modifications is recognizing the nature of the relationship between congestion and reliability. As with any economic externality, the 
tradeoff needs to be defined over the relevant range of demand. Current transmission policy endorsed by some ISOs and RTOs, and even the U.S. Congress errs in failing to realize these distinctions. Current policy treats the transmission system as if individual lines could be divided into those that benefit the system through added redundancy, and those that harm the system by causing congestion. Transmission lines are also treated as if their contribution to the system is independent of the state of the system. The RTO and FERC rationale for market-based merchant transmission is largely based on this false congestion-reliability dichotomy.

\section{Acknowledgements}

This work was funded by the Carnegie Mellon Electricity Industry Center, through grants from the Alfred P. Sloan Foundation, the Electric Power Research Institute, and the Tennessee Valley Authority. Any opinions and errors herein are those of the authors and should not be ascribed to the grantors.

The authors would like to thank Bill Hogan, Paul Joskow, Paul Hines, Jose Moura, Jeffrey Roark, Dmitri Perekhodtsev, Sarosh Talukdar, and Jay Apt for helpful comments and discussions.

\section{References}

Apt, J. and L. Lave, 2003. "Electric Gridlock: A National Solution," Public Utilities Fortnightly 141:18, pp. $14-17$.

Arnott, R. and K. Small, 1994. "The Economics of Traffic Congestion," American Scientist 82, pp. $446-455$.

Awad, M., S. Broad, K. Casey, J. Chen, A. Geevarghese, J. Miller, A. Sheffrin, M. Zhang, E. Toolson, G. Drayton, A. Rahimi, and B. Hobbs, 2004. "The California ISO Transmission Economic Assessment Methodology," paper presented at the first Carnegie-Mellon Conference on Electricity, Pittsburgh PA. Available at http://www.ece.cmu.edu/ electriconf/old2004/.

Baldick, R. and E. Kahn, 1993. "Transmission Planning Issues in a Competitive Economic Environment," IEEE Transactions on Power Systems 8:4, pp. 1497 - 1503.

Baldick, R., 2003. "Variation of Distribution Factors with Loading," IEEE Transactions on Power Systems 18:4, pp. 1316 - 1323.

Bean, N., F. Kelly, and P. Taylor, 1997. “Braess' Paradox in a Loss Network,” Journal of Applied Probability 4, pp. 155 - 159.

Blumsack, S., 2006a. Network Topologies and Transmission Investment Under Electric Industry Restructuring, unpublished Ph.D. Dissertation, Department of Engineering and Public Policy, Carnegie Mellon University. Available at http://www.andrew.cmu.edu/ sblumsac. 
Blumsack, S., 2006b. "Network Decomposition via Graph Theory," working paper, available at http://www.andrew.cmu.edu/ sblumsac/decomp.pdf.

Blumsack, S., J. Apt and L. Lave, 2006. "Lessons From the Failure of U.S. Electricity Restructuring," Electricity Journal 19:2, pp. 15 - 32.

Blumsack, S., M. Ilić, and L. B. Lave, 2006. "Congestion and Reliability in Electric Power Networks - Theory," working paper.

Bohn, R., M. Caramanis and F. Schweppe, 1984. "Optimal Pricing in Electrical Networks Over Space and Time," Rand Journal of Economics 15:3, pp. 360 - 376.

Braess, D., 1968. "Über ein Paradoxon aus der Verkehrsplanung," Unternehmensforschung 12, pp. 258 - 268.

Bushnell, J. and S. Stoft, 1996. "Electric Grid Investment Under a Contract Network Regime," Journal of Regulatory Economics 10, pp. 61 - 79.

Bushnell, J. and S. Stoft, 1997. "Improving Private Incentives for Electric Grid Investment," Resource and Energy Economics 19, pp. 85 - 108.

Calvert, B. and G. Keady, 1993. "Braess' Paradox and Power Law Nonlinearities in Networks," Journal of the Australian Mathematical Society B 35, pp. 1 - 22.

Chao, H. and S. Peck, 1996. "A Market Mechanism for Electric Power Transmission," Journal of Regulatory Economics 10, pp. 25 - 59.

Coxe, R. and M. Ilić, 1998. "System Planning Under Competition," in Power Systems Restructuring: Engineering and Economics, M. Ilić, F. Galiana, L. Fink, eds., Kluwer Academic Publishing, Boston MA.

Crew, M. and P. Kleindorfer, 1979. Public Utility Economics, St. Martins Press, New York, NY.

Duffin, R., 1965. "Topology of Series-Parallel Networks," Journal of Mathematical Analysis and Applications 10, pp. $303-318$.

Ejebe, G. and B. Wollenberg, 1979. "Automatic Contingency Selection," IEEE Transactions on Power Apparatus and Systems PAS-98, pp. 97 - 109.

Ekelöf, S., 2001. "The Genesis of the Wheatstone Bridge," Engineering Science and Education Journal 10:1, pp. 37 - 40.

Gribik, P., D. Shirmohammadi, J. Graves, and J. Kritikson, 2005. "Transmission Rights and Transmission Expansions," IEEE Transactions on Power Systems 20:4, pp. 1728 1737. 
Hebert, C., 2004. "Profit Without Costs," Public Utilities Fortnightly, 142:8, pp. 40 - 48.

Hirst, E., 2004. "U.S. Transmission Capacity: Present Status and Future Prospects," Edison Electric Institute and U.S. Department of Energy working paper.

Hogan, W., 1992. “Contract Networks for Electric Power Transmission,” Journal of Regulatory Economics 4: pp. 211 - 242.

Joskow, P., 2005a. "The Difficult Transition to Competitive Electricity Markets in the U.S.," in Electricity Deregulation: Choices and Challenges, J. Griffin and S. Puller, eds., University of Chicago Press, Chicago.

Joskow, P., 2005b. "Patterns of Transmission Investment," working paper, available at http://econ-www.mit.edu/faculty/index.htm?prof_id=pjoskow\&type=paper.

Joskow, P. and J. Tirole, 2000. "Transmission Rights and Market Power on Electric Power Networks," RAND Journal of Economics 31:3, pp. 450 - 487.

Joskow, P. and J. Tirole, 2005. "Merchant Transmission Investment," Journal of Industrial Economics 53:2, pp. 233 - 264.

Joskow, P. and J. Tirole, 2006. "Reliability and Competitive Electricity Markets," RAND Journal of Economics, forthcoming.

Korilis, Y., Lazar, A., and A. Orda, 1997. "Capacity Allocation Under Non-Cooperative Routing," IEEE Transactions on Automatic Control 42, pp. 309 - 325.

Korilis, Y., Lazar, A., and A. Orda, 1999. "Avoiding the Braess Paradox in Non-Cooperative Networks," Journal of Applied Probability 36, pp. 211 - 222.

Lecinq, B. and M. Ilić, "Peak-load Pricing for Transmission Access," Proceedings of the Hawaii International Conference on System Sciences, January 1997, pp. 624-633.

Milchtaich, I., 2005. "Network Topology and Efficiency of Equilibrium,” Bar-Ilan University Department of Economics Working Paper.

New York ISO, 2005. “Opportunities for New Transmission Investment in NYISO's Markets," Staff Presentation, available at http://www.nyiso.com/public/webdocs/services/planning/transmission_investments_work shop/Buechler_presentation_12052005.pdf

Oren, S., 1997. "Economic Inefficiency of Passive Transmission Rights in Congested Electricity Systems with Competitive Generation," Energy Journal 18, pp. 63 - 83. 
Patiño-Echeverri, D. and B. Morel, 2006. “An Options Theory Method to Value Electricity Financial Transmission Rights," Carnegie Mellon Electricity Industry Center working paper, available at http://wpweb2.tepper.cmu.edu/ceic/publications.htm.

Roark, J., 2006. "Redefining Merchant Transmission and Making it Happen," presented at the $2^{\text {nd }}$ Carnegie Mellon Conference on Electric Power, January 2006, available at http://www.ece.cmu.edu/ electriconf/Roark_ReDefining\%20Merchant\%20Transmission. pdf.

Sauer, P., 1981. "On the Formulation of Power distribution Factors for Linear Load Flow Methods," IEEE Transactions on Power Apparatus and Systems PAS-100:2, pp. 764 769.

Sauma, E. and S. Oren, 2006. "Proactive Planning and Valuation of Transmission Invesetments in Restructured Electricity Markets," Journal of Regulatory Economics, forthcoming.

Shanker, R., 2003. "Drawing the Line for Transmission Investment," Harvard Energy Policy Group working paper, available at http://www.ksg.harvard.edu/hepg/Papers/Shanker_Line.transm.investment_4-03.pdf.

Siddiqui, A., E. Bartholomew, C. Marnay and S. Oren, 2005. "On the Efficiency of the New York Independent System Operator Market for Transmission Congestion Contracts," Journal of Managerial Finance, 31:1, pp. 1-45.

Vogelsang, I., 2001. "Price Regulation for Independent Transmission Companies," Journal of Regulatory Economics 20:2, pp. 141 - 165.

Vogelsang, I., 2004. "Transmission Pricing and Performance-Based Regulation," presented at the 1st Carnegie Mellon Conference on Electric Power, December 2004, available at http://www.ece.cmu.edu/ electriconf.

Wood, A, and B. Wollenberg, 1996. Power Generation, Operation and Control, John Wiley \& Sons, New York.

Wu, F., P. Varaiya, P. Spiller, and S. Oren, 1996. "Folk Theorems on Transmission Access: Proofs and Counterexamples," Journal of Regulatory Economics 10, pp. 5 - 23.

Yu, C., J. Leotard and M. Ilić, 1999. "Dynamic Transmission Provision in Competitive Electric Power Industry," Discrete Event Dynamic Systems: Theory and Applications, 9, pp. 351-388, Kluwer Academic Publishers, Boston, MA. 